\title{
The effect of varied types of steel fibers on the performance of self-compacting concrete modified with volcanic pumice powder
}

\author{
Hassan M. Magbool, Abdullah M. Zeyad* \\ Department of Civil Engineering, College of Engineering, Jazan University, Jazan, Saudi Arabia
}

\begin{abstract}
The aim of this work involves studying the impact of varied types of steel fibers (SF) on the performance of self-compacting concrete (SCC), containing volcanic pumice powder (VPP). In this study, five types of steel fiber, which had a hooked end with two lengths of (SF1) and (SF3), flat end of length (SF2), in addition to the pointed end of (SF4) and (SF5) by $1 \%$ of volume fraction, were used. In addition, hybrid steel fiber (a mixture of all the steel fiber types) by $0.2 \%$ of volume fraction of concrete volume was used. Moreover, VPP was utilized by $30 \%$ cement mass as a substitute material for producing SCC. The impact of steel fiber properties in the shape of SF on the fresh concrete properties as slump flow and segregation were investigated. In addition to their influence on the compressive strength, s plit tensile strength, flexural strength, toughness, porosity, water absorption, and bulk density were examined. The results showed that SF led to decreasing the SCC fresh properties. Utilizing SF, on the other hand, improved the SCC hardened properties, as well as the toughness indices.
\end{abstract}

Keywords: self-compacting concrete, steel fiber, volcanic pumice powder, aspect ratios, workability, mechanical properties

\section{Introduction}

Self-compacting concrete (SCC) is a special type of concrete mixture with a high flowing ability and compacted under its weight, which can spread into a place, fill the formwork, and encapsulate the reinforcement without segregation, excessive bleeding, and any mechanical consolidation [1]. Furthermore, because of the need for concrete of high passing and capability, as well as filling-ability at a low cost, SCC is extremely beneficial in the manufacture of intricate concrete structures. Recently, it has enjoyed substantial significance due to its advantages. SCC is widely utilized in numerous countries for various applications, as well as in structural configurations. Often, this concrete contains a bulky quantity of powder materials, which are necessary for maintaining adequate yield value, in addition to the viscosity of the fresh mixture, and thereby decreasing segregation, bleeding, and settlement. Using fine materials of industrial waste, such as silica fume,

*E-mail: azmohsen@jazanu.edu.sa fly ash, and ground granulated blast-furnace slag, is an important factor for producing SCC that is compliant with the standard specifications. For example, Uysal et al. [2] used powdered limestone, basalt, and marble; Jalal et al. [3] used fly ash, nano silica, and silica fume, while Dadsetan and Bai [4] used metakaolin, ground granulated blastfurnace slag, and fly ash for producing SCC. Siddique [5] advocated utilizing volcanic ash (VA) in cement, mortar, and concrete, which supported the results of previous studies [6]. In addition, Etli et al. [7] reported that the self-compacting mortars produced with pumice powder improved both the fresh and hardened state features of the mortar. Moreover, Granata [8] recommended utilizing volcanic pumice powder (VPP), which includes pozzolanic properties for the potential use of powdered pumice in SCC manufacture. As established, however, the chemical composition of VPP varies widely with the source or location [9]. Therefore, the improved results or performances can be because of the mineralogical components, the characteristics of particle size, and the ash formation circumstance [10]. In the Southwestern Arab Peninsula [11], and in the 
western parts of the United States [12] are found abundant amounts of VA classified as a natural pozzolanic material, whose physical and chemical characteristics showed that there is great potential for using it as a supplementary, cementitious material.

In general, SCC is the same as ordinary concrete, exhibiting poor resistance to tensile strength and the growth of cracks. Burati et al. [13] reported that the addition of fibers is essential for enhancing the post-peak behavior and mechanical properties of SCC. Besides, according to Dhonde et al. [14], fiber-reinforced SCC (SCFs) can mitigate two opposing weaknesses: poor workability in fiber concrete mixtures and cracking resistance in plain concrete. Adding fibers to SCC represents a relatively innovative composite material, combining the SCC technology benefits with the fiber advantages of the hard-cementitious matrix.

SCFs have become an important option for increased durability (i.e., reducing limited crack widths) or for safety considerations and design criteria. The performance (strength and hardness) of SCC has shown improvement by connecting crack bridges, transmitting stresses across cracks, and addressing them, and preventing crack growth. Regarding the inclusion of fibers in the SCC mix design, steel fibers (SFs) are more common in concrete production compared to plastic, glass, and carbon [15]. There are various kinds of SFs such as hooked-end, flat-end, smooth, deformed sheet, straight-end, and curved fiber [16]. Zemir et al. [17] reported that the inclusion of steel fiber in SCC contributes to improving the mechanical properties. The physical properties of SFs affect the workability of the SCC, the shape of the fibers, the aspect ratio, the length of the fibers, and the size of the fibers per cubic meter of concrete. In general, the physical properties, which reduce workability, play a positive role by increasing the performance of the SFs and, thus, increasing the durability of concrete. Therefore, to solve the problem of decreased operability, it is necessary to obtain the optimal solution of the types of SFs that match the performance and workability of SCC. Madandoust et al. [18] reported that increasing the volume fraction of SFs leads to a decrease in work- ability. The optimal fiber volume fraction in SCC depends on the type of fiber used [19]. In previous research on the workability of fiber-reinforced concrete, Ponikiewski [20] found that the workability and rheological properties exert a substantial influence on the placement of the fibers within concrete. Moreover, Martini and Russell [21] reported a robust relationship between the fresh properties and the mechanical properties of hardened concrete. Although some studies have been carried out on the optimization of the mixture proportion for the addition of fibers to SCC, the fibers' actual impact on the characteristics of the flexural toughness of SCFs has not been adequately understood. This can be attributed to the inadequacies of the characterization of the standard toughness experimental results.

This paper aims to examine the SCC flexural toughness characteristics, incorporating VPP as well as various SFs. Five types were selected from the most popular fibers with various aspect ratios and shapes, including hooked-end $(60 \mathrm{~mm}$ and 30 $\mathrm{mm}$ ), straight (21 $\mathrm{mm}$ and $13 \mathrm{~mm}$ ), and flat-end fibers to produce six concrete mixtures. All fibers were added to the concrete mixtures at a $1 \%$ by volume fraction to produce SCFs. Subsequently, VPP was used at a $30 \%$ replacement rate of cement mass. Thus, to assess workability, as well as the rheological properties, slump flow, L-box, segregation, and bleeding were performed on the fresh concrete. An average of three samples of every test was documented on the hardened concrete. Also, a toughness concrete test at 28 days was conducted. The absorption and porosity aged at 28 . The hardened concrete's compressive and flexural, along with tensile strengths aged at 7, 14, 28, and 90 days were examined as well.

\section{Materials and methods}

\subsection{Materials}

\subsubsection{Cement}

This study used Ordinary Portland cement (OPC), type I of OPC utilized according to ASTM C150 [22] Tables 1 and 2 illustrate the physical properties and chemical composition of OPC, re- 
spectively.

Table 1. Physical properties of VPP and cement.

\begin{tabular}{|c|c|c|}
\hline Property & $\mathrm{VPP}$ & Cement \\
\hline Relative density & 2.61 & 3.10 \\
\hline Surface area $\left(\mathrm{cm}^{2} / \mathrm{g}\right)$ Blaine method & 3.970 & 3.530 \\
\hline Median diameter $(\mu \mathrm{m})$ & 6.3 & 9.2 \\
\hline
\end{tabular}

VPP, volcanic pumice powder.

Table 2. Chemical composition of VPP and cement.

\begin{tabular}{lll}
\hline Oxide & \multicolumn{2}{l}{ VPP $\%$ Cement \% } \\
\hline \hline $\mathrm{SiO}_{2}$ & 46.5 & 20.05 \\
$\mathrm{Al}_{2} \mathrm{O}_{3}$ & 17.59 & 4.93 \\
$\mathrm{Fe}_{2} \mathrm{O}_{3}$ & 7.33 & 3.90 \\
$\mathrm{CaO}$ & 12.52 & 61.57 \\
$\mathrm{MgO}$ & 6.94 & 0.81 \\
$\mathrm{Na}_{2} \mathrm{O}$ & 2.58 & 0.08 \\
$\mathrm{TiO}_{2}$ & 1.41 & 0.24 \\
$\mathrm{~K}_{2} \mathrm{O}$ & 1.17 & 1.33 \\
$\mathrm{P}_{2} \mathrm{O}_{5}$ & 0.71 & 0.08 \\
$\mathrm{SO}_{3}$ & 0.42 & 3.06 \\
$\mathrm{MnO}_{\mathrm{Cl}}$ & 0.14 & 0.19 \\
$\mathrm{Cl}$ & 0.01 & - \\
$\mathrm{LOI}_{\mathrm{SiO}}+\mathrm{Al}_{2} \mathrm{O}_{3}+\mathrm{Fe}_{2} \mathrm{O}_{3}$ & 76.01 & - \\
\hline
\end{tabular}

VPP, volcanic pumice powder.

\subsubsection{Volcanic pumice powder (VPP)}

VPP was used in this study at $30 \%$ partial replacement of cement mass. Moreover, VPP was obtained from a quarry to produce lightweight aggregates in the Jazan region, Saudi Arabia, as shown in Figure 1. The VPP was collected from waste materials resulted from crushing volcanic pumice. The collected VPP was passed through a sieve of $150 \mathrm{~mm}$ to remove the bigger particles. Then, the VPP was refined by balls mill to produce fine powder with an average diameter of $4.96 \mu \mathrm{m}$ (Figure 2). The VPP physical properties and cement are displayed in Tables 1 and 2, which illustrate the chemical composition of VPP and cement. The fine VPP chemical properties met the ASTM C618 PM specification requirements as reported in a previous study [23].

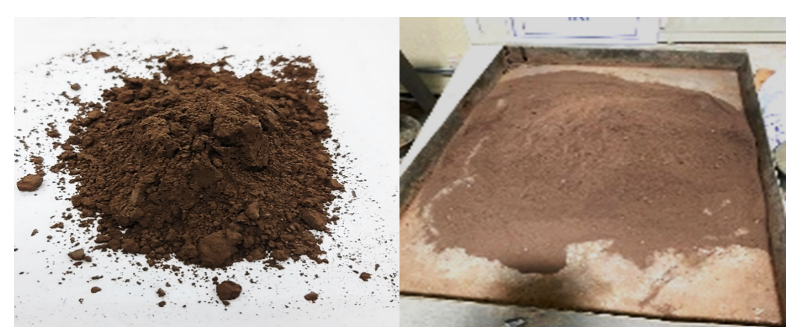

Fig. 1. The VPP used in this research. VPP, volcanic pumice powder.

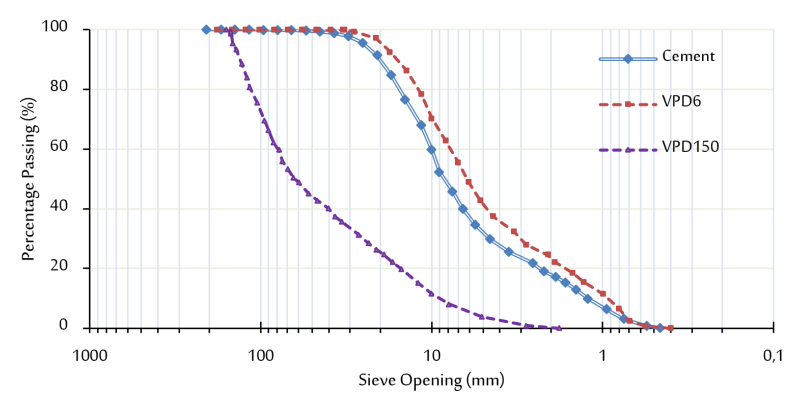

Fig. 2. Sieve analysis of cement and VPP. VPP, volcanic pumice powder.

The chemical composition of cement and VPP were measured by X-Ray Fluorescence (XRF) test, using the X-ray spectrometer Rigaku RIX 3000. The XRF analysis was carried out according to BS EN ISO 12677 [24].

\subsubsection{Aggregate}

A crushed limestone rock with a maximum size of $12.7 \mathrm{~mm}$ in the concrete mixture was used as gravel, while natural desert sand was used as sand. The gravel and sand showed $1.1 \%$ and $1.6 \%$ water absorption and 2.67 and 2.70 specific gravities, respectively. The gravel and sand met the specification of ASTM C33 [25]. Figure 3 shows the grading of fine and coarse aggregate.

\subsubsection{Steel fibers (SFs)}

Five fiber types were utilized for the preparation of SCC samples. The types of fibers included a hook-end of $60 \mathrm{~mm}$ in length (SF1), a hook-end of $30 \mathrm{~mm}$ in length (SF3), a flat-end of $50 \mathrm{~mm}$ 


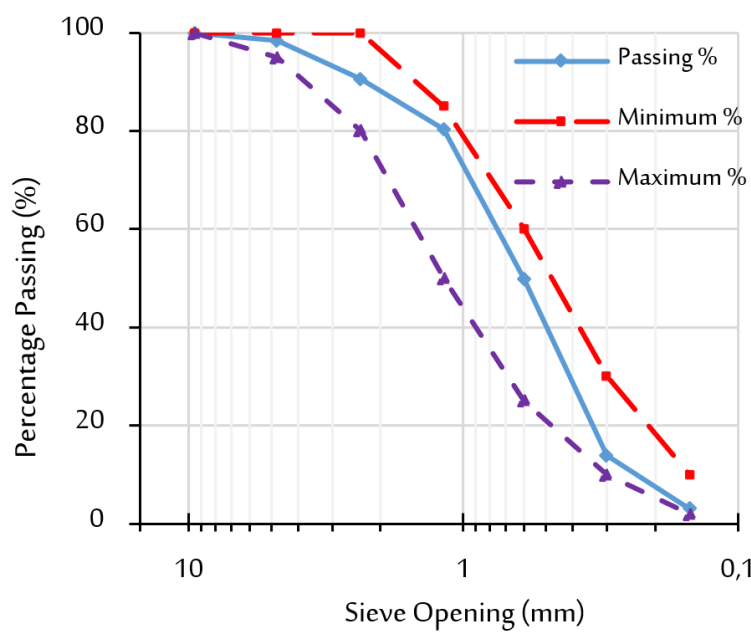

(a)

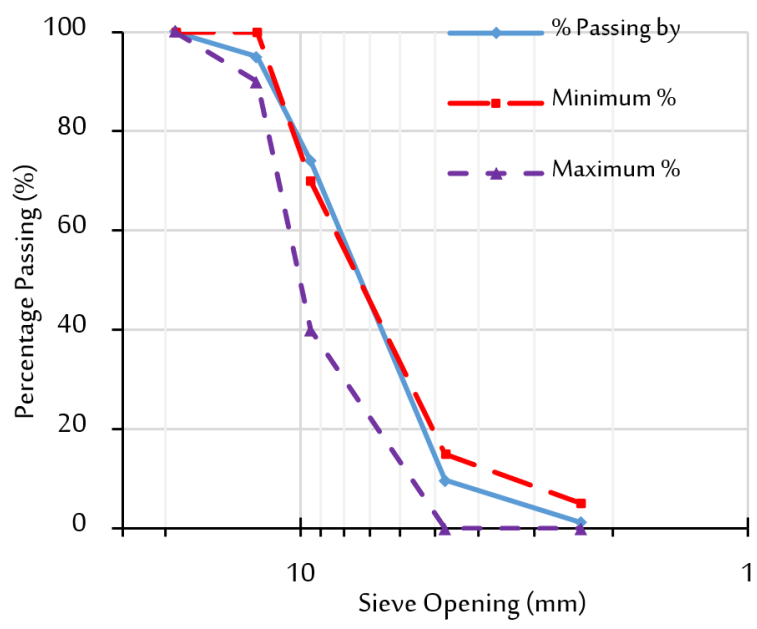

(b)

Fig. 3. Sieve analysis aggregate (A) for sand and (B) for gravel.

in length (SF2), as well as microfibers measuring $21 \mathrm{~mm}$ (SF4) and $13 \mathrm{~mm}$ in length (SF5). In addition, there was application of hybrid fibers at $0.2 \%$ for each of the five types. The SF volume fraction used in this research was $1 \%$ of concrete volume; this percentage has been suggested based on several studies that recommend adding $0.5 \%$ to $2 \%$ of SFs as the ideal percentage of the concrete volume fraction, so that decline in the fresh concrete properties and strength can be avoided [26]. Table 3 reports the characteristics of these fibers.

\subsubsection{Admixtures}

Superplasticizer (SP) Sicka 1050 was used in this study for SCC production and SCFs. The SP properties are provided in Table 4.

\subsection{Mixture proportioning}

The first control mixture (SCC) without fibers was designed as a plain SCC. The SCC mixture was designed with used VPP as partial replacement of cement by $30 \%$. The design method of the SCC mixture differs considerably from the design of normal concrete. There are important requirements for the mixture design method, estimating the required weights, which include the aggregate selection of max size of $12.7 \mathrm{~mm}$, and the best proportion to allow easy passing capability. Also, required are cementitious materials, the water ratio, the mortar, and the paste volume fraction for producing the SCC with the desired slump flow without bleeding or segregation. The design of the concrete mixture was according to the specification ACI 211.1-91 [27]. These steps with the appropriate admixture of SP added should be applied in a lab to ensure good fresh SCC properties. After getting the SCC mixture the SF of volume fraction $1 \%$ was added to the mixture to produce SCFs. Table 5 shows the concrete mixture proportions.

The mixing program began by placing the gravel, sand, and cementitious (cement and VPP) in the mixer, then mixing the dry materials for 2 min. After that, $70 \%$ of the water containing the SP was added to the mixer; the mixing process continued for $3 \mathrm{~min}$. Finally, SF was added to the mixture and the mixing process continued for $3 \mathrm{~min}$ until the mixture was fully homogenized. After the mixing process was completed, fresh concrete tests were carried out directly. Then, the concrete was put into molds without using the vibrator. After the specimens were stored for $24 \mathrm{~h}$ in laboratory conditions, applied according to ACI 308R-01 R08 [28], they were removed from the molds.

\subsection{Test specimens}

To identify the properties of SCC in a fresh concrete state, slump flow and L-box tests were conducted in accordance with EFCAA [29]. In addi- 
Table 3. Physical properties of VPD and cement.

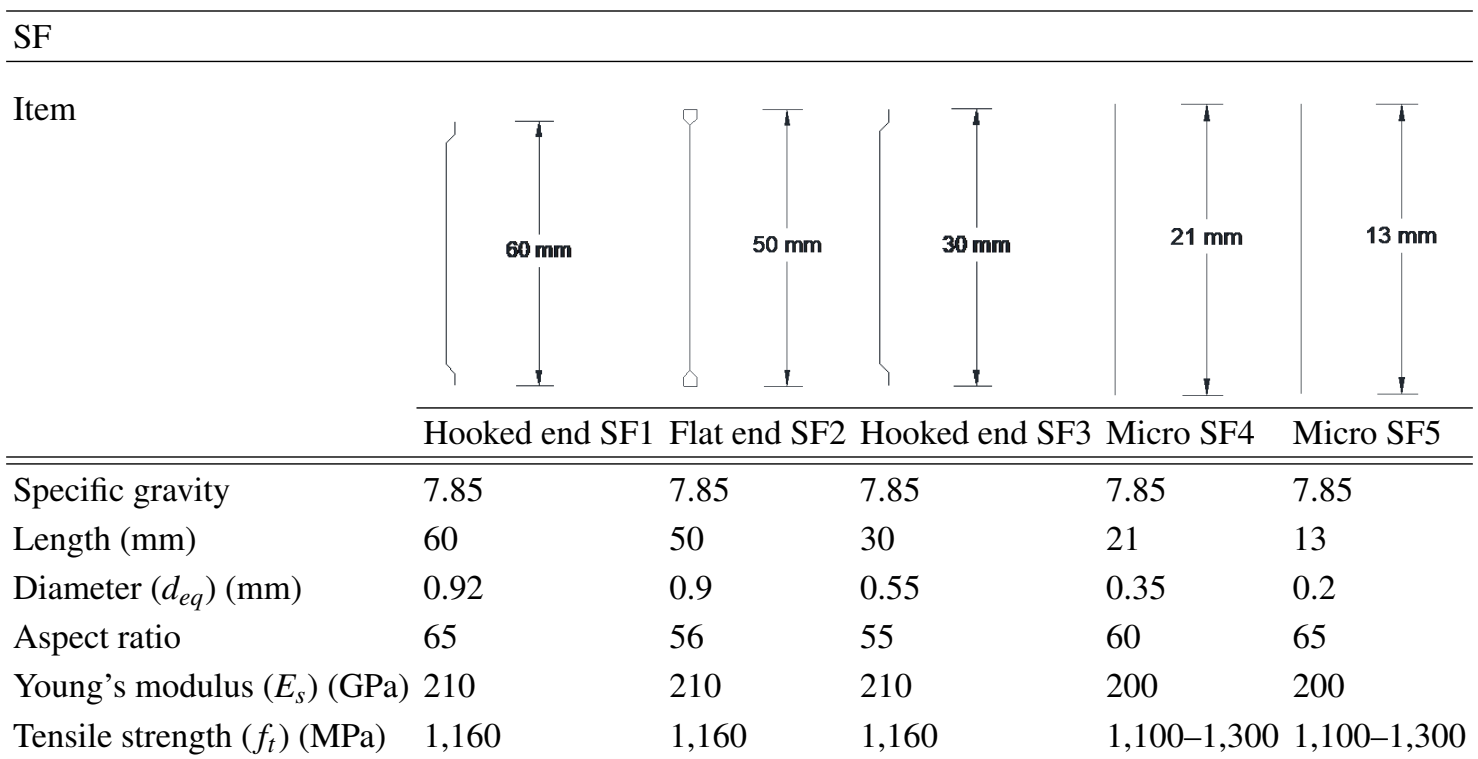

SF, steel fibers.

Table 4. Copolymer-based SP properties.

\begin{tabular}{ll}
\hline Properties & Information \\
\hline \hline Chemical base & Modified polycarboxylate in water \\
Color & Liquid/turbid to light yellowish \\
Density & $1.070\left(20^{\circ} \mathrm{C}\right)$ \\
Chloride ion content & $<0.1 \% \mathrm{w} / \mathrm{w}$ \\
Alkaligehalte & $<0.5 \% \mathrm{w} / \mathrm{w}$ \\
\hline
\end{tabular}

SP, superplasticizer.

tion, the segregation and bleeding tests were conducted according to ASTM C1610 [30] and ASTM C232 [31]. To ensure that there was no workability loss influence on the results of the samples of fresh concrete, these tests were carried out within $15 \pm 5$ min of adding water. The tests of the hardened concrete included nine samples for every compressive, indirect tensile, flexural strength, and toughness (Figure 4). The standard cylinder $10 \mathrm{~cm}$ diameter $\times 20 \mathrm{~cm}$ height for the compressive and indirect tensile tests were used, respectively. The tests were conducted according to ASTM C39 [32] and ASTM C496 [33] for the compressive and indirect tensile tests, correspondingly. Flexural strength and toughness, and first-crack strength were used as standard beam dimensions of $10 \mathrm{~cm} \times 10 \mathrm{~cm} \times 50$ $\mathrm{cm}$ under three-point loading on a span of $300 \mathrm{~mm}$ following ASTM C78 [34] and ASTM C1018 [35], respectively. The compressive and indirect tensile tests were recorded for a total of three samples at ages of 7, 28, and 90 days. However, flexural strength, toughness, and first-crack strength were on three samples at 28 days.

\section{Results and discussion}

\subsection{Properties of fresh concrete}

Table 6 presents the fresh state properties of concrete mixtures studied. The test of slump flow tested the concrete capability of deforming under its weight set against the surface friction without restraint, and the obtained slump flow value ranging between and $700 \mathrm{~mm}$ of the SCC has been suggested [29]. The SCC, SCF3, and SCF6 mixtures conformed to the above-mentioned range. However, slump flow of SCF1, SCF2, SCF4, and SCF5 dropped below the minimum requirement (i.e., $500 \mathrm{~mm}$ ) with slightly decreased ratios of $11.11 \%, 4.17 \%, 2.04 \%$, and $11.11 \%$. Thus, the Lbox ratio $\mathrm{H}_{2} / \mathrm{H}_{1}$ of the given $\mathrm{SCC}$ mixture recorded over 0.92 , which is restricted in accordance with the standards of EFCAA [29] and with other mixes, 
Table 5. Properties of concrete mixture.

\begin{tabular}{|c|c|c|c|c|c|c|c|c|c|c|c|}
\hline Mixture & $\frac{\text { Cement }}{\left(\mathrm{kg} / \mathrm{m}^{3}\right)}$ & VPP & Gravel & Sand & SF1 & SF2 & SF3 & SF4 & SF5 & Wat & SP \\
\hline SCC & 350 & 150 & 801 & 822 & - & - & - & - & - & 220 & 6.5 \\
\hline SCF1 & 350 & 150 & 801 & 795 & 78.4 & - & - & - & - & 220 & 6.5 \\
\hline SCF2 & 350 & 150 & 801 & 795 & - & 78.4 & - & - & - & 220 & 6.5 \\
\hline SCF3 & 350 & 150 & 801 & 795 & - & - & 78.4 & - & - & 220 & 6.5 \\
\hline SCF4 & 350 & 150 & 801 & 795 & - & - & - & 78.4 & - & 220 & 6.5 \\
\hline SCF5 & 350 & 150 & 801 & 795 & - & - & - & - & 78.4 & 220 & 6.5 \\
\hline SCF6 & 350 & 150 & 801 & 795 & 15.6 & 15.6 & 15.6 & 15.6 & 15.6 & 220 & 6.5 \\
\hline
\end{tabular}

SCC, self-compacting concrete; SFs, steel fibers; SP, superplasticizer; VPP, volcanic pumice powder.

comparatively. It has also been detected that the workability of the mixture has been adversely influenced by the existence of fibers. This has ultimately led to less SCC flowability. It is worth mentioning that these results were in good agreement with the results in [26, 36]. As observed in Table 6, despite adding SF, the density of fresh concrete remained nearly constant because of increase in the air content [37]. Adding SF or other types to concrete led to reducing the fresh properties of SCC. This result agrees with the result in a previous study, which used hook-end steel, polypropylene, mild steel, curved steel, and basalt rock [38]. Figure 5 displays the obtained segregation and the bleeding test results of SCC, SCF1, SCF2, SCF3, SCF4, SCF5, and SCF6. Based on the results, it was seen that the addition of fibers led to a significant decrease in the segregation rates, approximately ranging between $22.92 \%$ and $43.75 \%$ for the SCC. On the other hand, using the SF3 to SCC contributed to decreased segregation rates of $14.28 \%, 16.92 \%, 20.59 \%, 27.03 \%$, and $8.47 \%$ of SCF1, SCF2, SCF4, SCF5, and SCF6, respectively. These results confirmed that SF can be utilized for reducing the SCC segregation rate. As shown by the results (refer to Figure 5), adding fibers resulted in a clear decrease in the bleeding rate of 0.21 $\mathrm{ml} / \mathrm{kg}$ for SCC. The reduction ratios were $9.52 \%$, $14.29 \%, 23.81 \%, 42.86 \%, 42.86 \%$, and $28.57 \%$ for SCF1, SFC2, SFC3, SFC4, SFC5, and SFC6, correspondingly. Figure 6 displays the relationship between the segregation and bleeding tests of all SCC mixtures. Also, the correlation between the segre- gation and bleeding results is shown in Eq. (1).

$$
\begin{aligned}
& \text { Segregation } \%=932 \times(\text { bleeding })^{2}- \\
& -221.68 \times(\text { bleeding })+18.883
\end{aligned}
$$

In a previous study by Zeyad and Abutaleb [39], the effect of replacing $20 \%$ of the cement mass by VPP and SF on the properties of SCC was studied. The proportions of the mixture differed slightly as a result of the mix design and trial mixes (VPP, water, and SP were 100,200 , and $8 \mathrm{~kg} / \mathrm{m}^{3}$, respectively). The previous results, thus, agree with the results of this study. The mixture, without replacing the cement by VPP, achieved the following results: 690 $\mathrm{mm}, 0.85,23 \%, 0.36 \mathrm{ml} / \mathrm{cm}^{2}$ for slump flow, Lbox, segregation, and bleeding, respectively. However, the test results when $20 \%$ of the cement mass was replaced by VPP were as follows: $710 \mathrm{~mm}$, $0.89,10.1 \%, 0.18 \mathrm{ml} / \mathrm{cm}^{2}$ for slump flow, L-box, segregation, and bleeding, respectively. Therefore, there is an agreement between the results of the previous study with the obtained results in this study. The reason, however, behind such slight differences between both studies can be attributed to the different proportions of mixing.

\subsection{Hardened concrete properties}

\subsubsection{Absorption and porosity}

Table 7 presents the absorption and porosity of the concrete mixtures studied. As shown in Table 7 , the absorption of concrete mixtures increased by adding SF to concrete. An average increase in 
Table 6. The SCC mixtures fresh state characteristics.

\begin{tabular}{llllll}
\hline \multirow{2}{*}{ Mixture } & L-box & \multicolumn{3}{c}{ Slump flow Segregation } & Bleeding Density \\
\cline { 2 - 6 } & Ratio & $(\mathrm{mm})$ & $\%$ & $\left(\mathrm{ml} / \mathrm{cm}^{2}\right)$ & $\left(\mathrm{kg} / \mathrm{m}^{3}\right)$ \\
\hline \hline SCC & 0.92 & 690 & 9.6 & 0.21 & 2,336 \\
SCF1 & Restricted & 450 & 6.3 & 0.19 & 2,269 \\
SCF2 & Restricted 480 & 6.5 & 0.18 & 2,321 \\
SCF3 & Restricted & 520 & 5.4 & 0.16 & 2,315 \\
SCF4 & Restricted 490 & 6.8 & 0.12 & 2,276 \\
SCF5 & Restricted & 480 & 7.4 & 0.12 & 2,304 \\
SCF6 & Restricted & 510 & 5.9 & 0.15 & 2,219 \\
\hline
\end{tabular}

SCC, self-compacting concrete.

Table 7. The absorption and porosity of SCC mixtures.

\begin{tabular}{lllllllll}
\hline & SCC & SCF1 & SCF2 & SCF3 & SCF4 & SCF5 & SCF6 \\
\hline \hline Porosity \% & 15 & 16.10 & 16.02 & 16.90 & 16.30 & 16.74 & 18.12 \\
Absorption \% & 7.33 & 7.64 & 7.42 & 7.88 & 7.71 & 7.84 & 9.03 \\
\hline
\end{tabular}

SCC, self-compacting concrete.

absorption in the entire mixtures ranged approximately between $1.23 \%$ and $23.19 \%$, with the inclusion of fibers in the mixtures. As shown in Table 7, adding SF to concrete increased the porosity between $0.38 \%$ and $13.53 \%$, compared with SCC. Besides, the small length fibers (i.e., SCF3 and SFC5) had high absorption and porosity compared with the large length fibers (i.e., SCF1 and SFC4), which can be attributed to the surface area of the short fiber, which is higher than the long fibers, and thus more spread in the concrete mixture. This increased the internal friction forces in the mixtures, thereby increasing the pores and the absorption in the mixtures of fiber concrete [40]. The use of VPP as a partial substitute for cement, on the other hand, significantly contributed to reducing the permeability of concrete, and this result has been reported by Zeyad and Al-Maliki in their study [41].

\subsubsection{Compressive strength}

The compressive strength at different ages of SCC, SCF1, SCF2, SCF3, SCF4, SCF5, and SCF6 mixtures are shown in Figure 7. All concrete mixtures containing fiber were higher than the SCC mixture. The increase in compressive strength of concrete containing fibers may be attributed to ar- resting of the growth of cracks, depending on the bond strength (i.e., confinement effect) of SF and the concrete matrix [42]. Also, SCF3 (i.e., the smaller hooked fiber) exhibited the highest compressive strength compared with all the mixtures, while SCF6 (i.e., hybrid fiber) had the lowest compressive strength in all fiber mixtures as displayed in Figure 7. The average compressive strength of SCF3 was $22.47 \%, 6.16 \%, 5.56 \%, 4.49 \%, 8.99 \%$, and $15.62 \%$ higher than the SCC, SCF1, SCF2, SCF4, SCF5, SCF6 mixtures, respectively. The results showed that the SCF3 mixture at 7 days was $29.78 \%, 5.17 \%, 4.45 \%, 5.90 \%, 8.54 \%$, and $19.14 \%$ higher than the SCC, SCF1, SCF2, SCF4, SCF5, SCF6 mixtures, respectively. A similar trend was detected for the compressive strength of the SCF3 mixture at 90 days, that is, it was $18.66 \%$, $6.20 \%, 5.08 \%, 3.12 \%, 8.53 \%$, and $14.55 \%$ higher than the SCC, SCF1, SCF2, SCF4, SCF5, and SCF6 mixtures, respectively. Furthermore, the results revealed that there exists a slight difference in compressive strength between the SCF1, SCF2, and SCF5 mixtures. 


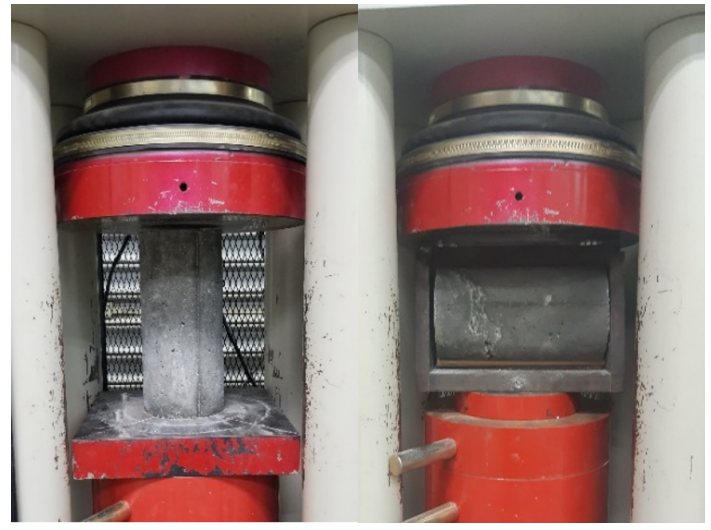

(a)

(b)

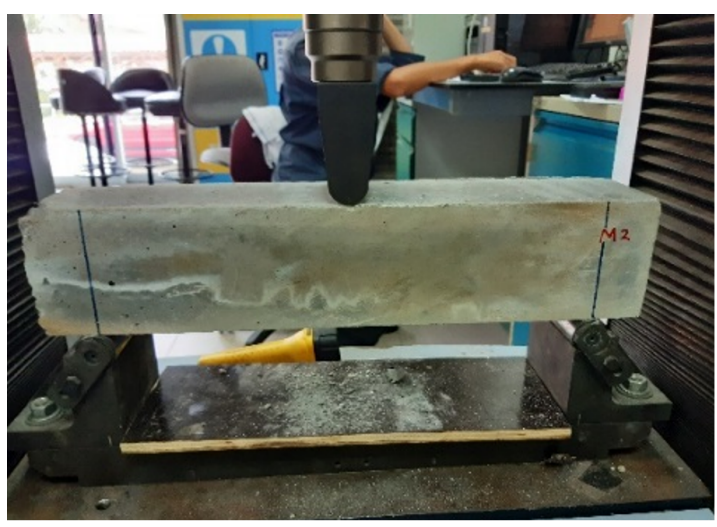

(c)

Fig. 4. Test setups for evaluating mechanical properties of concrete: (A) compression test; (B) indirect tensile; (C) flexural strength test.

\subsubsection{Indirect tensile strength}

The indirect tensile strengths (splitting tensile) of various concrete samples were determined after $7,14,28$, and 90 days; the average of three-cylinder in each type of concrete mixture was measured and is displayed in Figure 8. The indirect tensile strength was enhanced significantly when using SF in producing the SCF mixtures versus SCC. Therefore, the mixes' indirect tensile strength were 3.2 $\mathrm{MPa}, 3.93 \mathrm{MPa}, 3.82 \mathrm{MPa}, 4.06 \mathrm{MPa}, 4.35 \mathrm{MPa}$, $4.16 \mathrm{MPa}, 4.08 \mathrm{MPa}$ at 28 days for SCC, SCF1, SCF2, SCF3, SCF4, SCF5, and SCF6, correspondingly. Nevertheless, there was an increase in the indirect tensile strength by $6.56 \%, 5.59 \%, 4.97 \%$, $5.67 \%, 3.68 \%, 4.57 \%$, and $2.94 \%$ at 90 days for concrete mixtures of SCC, SCF1, SCF2, SCF3,

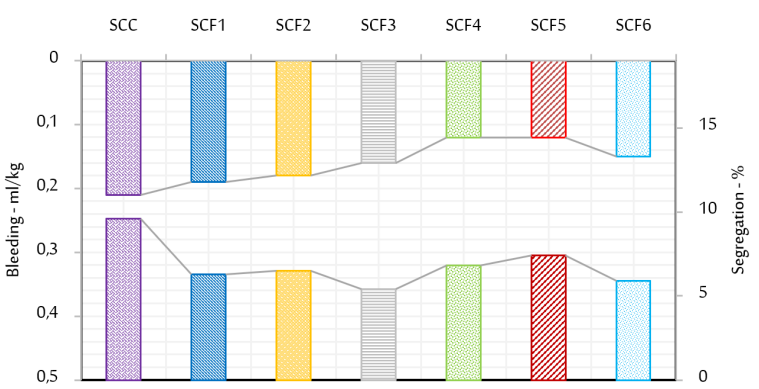

Fig. 5. Results of bleeding and segregation test of all concrete mixtures. SCC, self-compacting concrete; SCF, fiber-reinforced SCC.

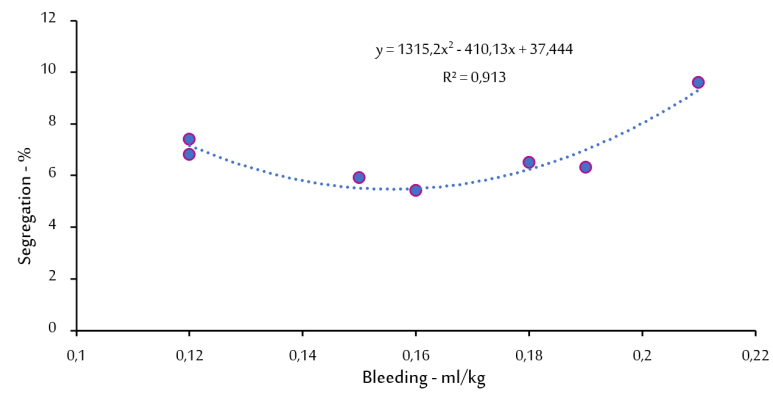

Fig. 6. Relationship between results of segregation and bleeding results.

SCF4, SCF5, and SCF6, respectively. The addition of SF to SCC significantly increased the indirect tensile strength at all test ages, as shown in Figure addition, SCF4 (i.e., larger Microfiber) exhibited the highest indirect tensile strength compared with all the other mixtures. As shown in this research, all fibers increase their indirect tensile strength capabilities by $>19.5 \%$. The existence of the fiber content enhances the characteristics of tensile strength due to the fibers' action in arresting and bridging the concrete matrix cracks; the forces of bridging are extremely dependent on the fiber type [43].

The compressive strength effects on the indirect tensile strength of SCC, SCF1, SCF2, SCF3, SCF4, SCF5, and SCF6 are shown in Figure 9. With increase in compressive strength, the indirect tensile strength also increased. Furthermore, the correlation between the compressive strength and indirect tensile strength results are shown in Eq. (2). 


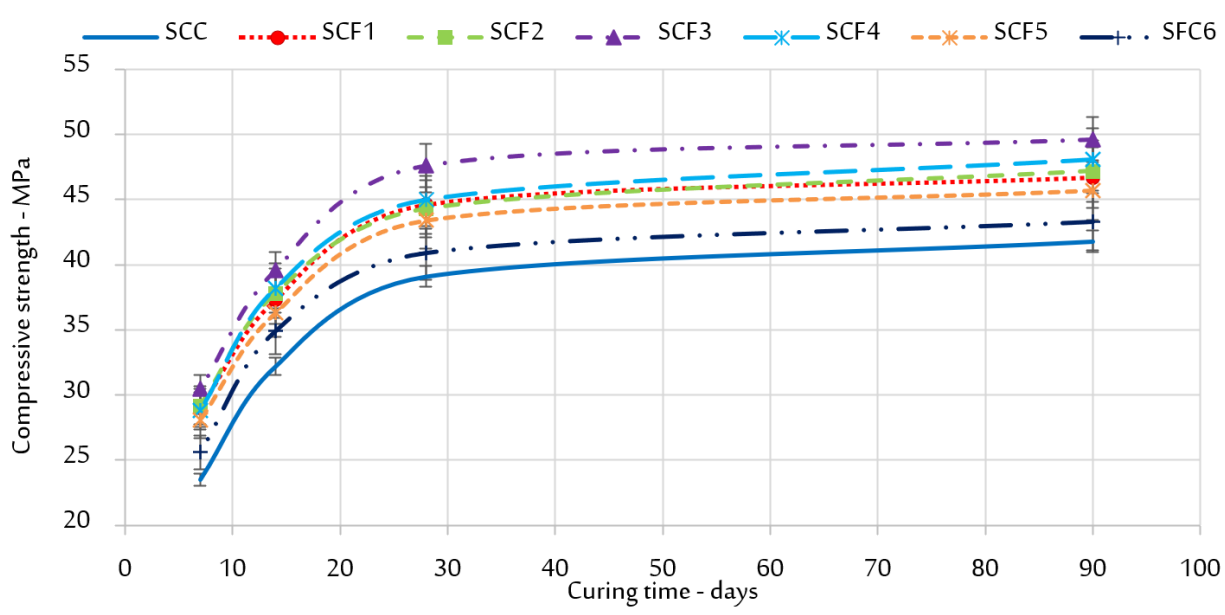

Fig. 7. Compressive strength of all mixtures at different ages. SCC, self-compacting concrete; SCF, fiberreinforced SCC.

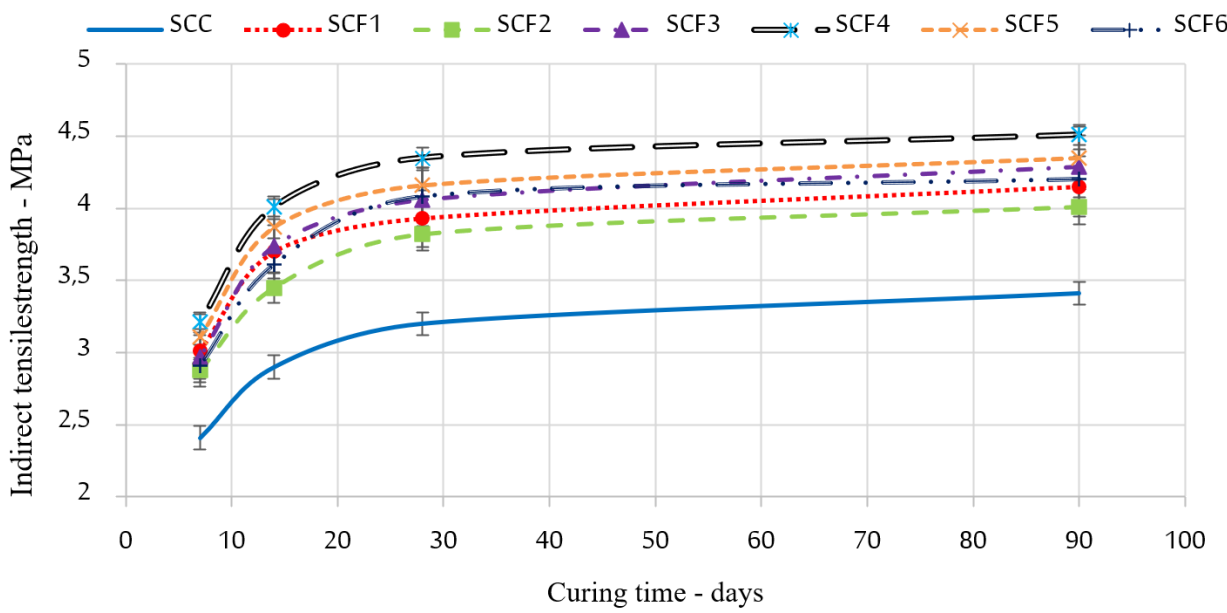

Fig. 8. Indirect tensile strength for all mixtures at different ages. SCC, self-compacting concrete; SCF, fiberreinforced SCC.

Compressive strength $=$

$$
=13.537 \times(\text { indirect tensile strength }-12.097)
$$

\subsection{Flexural toughness characterization}

Flexural toughness is a significant dimensionless parameter for evaluating the contribution of fibers on the changing of post-peak behavior in the load-deflection curve. Varied methods, including (ACI 544 and ASTM C 1018) were developed for calculating flexural toughness, in addition to concrete performance, which contains SF. In the fol- lowing section, the method specifications are provided.

\subsubsection{According to ASTM Standard Test Method (C 1018)}

According to ASTM C 1018 [35], the performance of SCF beams can be obtained under thirdpoint loading, by calculating the amount of energy required for first-crack deflection $\left(\delta_{c r}\right)$ and then to further deflect to specific multiples of the firstcrack deflection (i.e., $3 \delta_{c r}, 5.5 \delta_{c r}, 10.5 \delta_{c r}$, etc.) based on Figure 10.

The toughness index is determined by dividing 


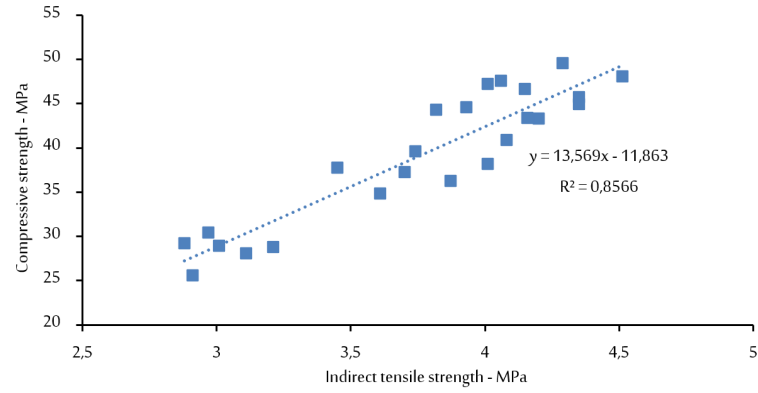

Fig. 9. Relationship between results of compressive and indirect tensile strength.

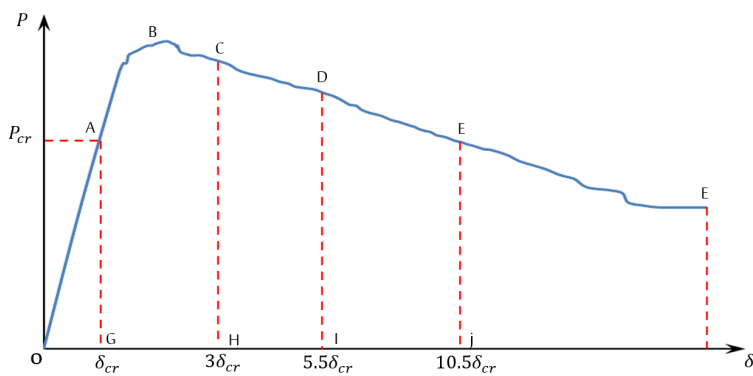

Fig. 10. Flexural toughness indices according to ASTM C 1018 [35].

the complete area under the load-deflection $(P-$ $\delta$ ) curve up to the given service level deflection by the area under the load-deflection curve up to the first-crack deflection. Toughness indices $I_{5}, I_{10}, I_{20}$, and so on, are determined on three service levels at $3,5.5,10.5$, times of the first-crack deflection, respectively, as described in Eqs. (3)-(5) [35].

$$
\begin{aligned}
& I_{5}=\frac{\text { Area }_{\mathrm{OABCHO}}}{\text { Area }_{\mathrm{OAGO}}} \\
& I_{10}=\frac{\text { Area }_{\mathrm{OABDIO}}}{\text { Area }_{\mathrm{OAGO}}} \\
& I_{20}=\frac{\text { Area }_{\mathrm{OABEJO}}}{\text { Area }_{\mathrm{OAGO}}}
\end{aligned}
$$

The residual strength factors $(R)$ can evaluate the average post-crack load retained over a specific deflection (i.e., 3 times, 5.5 times, and 10.5 times of the first-crack deflection) as described in Eqs. (6) and (7) [35].

$$
\begin{gathered}
R_{5,10}=20\left(I_{10}-I_{5}\right) \\
R_{10,20}=10\left(I_{20}-I_{10}\right)
\end{gathered}
$$

The index of toughness and the factors residual strength of plain concrete was equivalent to one and zero, correspondingly, due to the given brittle response. Thus, the energy at first-crack is very important because the entire performance parameters, i.e., $(I$ and $R$ ) were later calculated according to it. An accurate determination of the beams' deflection is also very important after the first crack. In this study, Eqs. (3)-(5) were used to calculate the toughness indices $I_{5}, I_{10}$, and $I_{20}$ through the areas under $P-\delta$ curves (Figure 11) related to 3, 5.5, and 10.5 , times of the first-crack deflection (i.e., $3 \delta_{\mathrm{cr}}, 5.5 \delta_{\mathrm{cr}}, 10.5 \delta_{\mathrm{cr}}$, etc.,). In addition, $I_{5}, I_{10}$, and $I_{20}$ were used to determine the residual strength factors $R_{5,10}$ and $R_{10,20}$ as described in Eqs. (6) and (7). Figures 12 and 13 show the areas under the curves of $3 \delta_{\mathrm{cr}}, 5.5 \delta_{\mathrm{cr}}$, and $10.5 \delta_{\mathrm{cr}}$, toughness indices, and residual strength factors for all concrete mixtures.

As shown in Figure 12A, the highest firstcrack loads value was recorded in the SCF3 mixture, while the lower first-crack loads value was recorded in the SCF6 mixture. The results revealed that the first-crack loads of the SCF1, SCF2, SCF4, SCF5, and SCF6 mixtures were different from the results of the SCF3 mixture, reaching $39.4 \%, 32.1 \%, 30.5 \%, 22.1 \%$, and $43.9 \%$, respectively. Moreover, the SCF6 exhibited the highest first-crack deflections compared with all the other mixtures, as shown in Figure 12B. The increase ratios were $86 \%, 10 \%, 8.5 \%, 46.2 \%$, and $70.4 \%$ for the SCF1, SCF2, SCF3, SCF4, and SCF5 mixtures, respectively.

According to the ASTM C 1018 [35] method (Figure $12 \mathrm{C}-\mathrm{F}$ ), the maximum increase in area under $P-\delta$ curves (Figure 11) up to first-crack deflection $\left(\delta_{\mathrm{cr}}\right)$ is provided by the SCF3 mixture with an increased ratio of 3.94 times. A similar phenomenon can be observed in $3 \delta_{\mathrm{cr}}, 5.5 \delta_{\mathrm{cr}}$, and $10.5 \delta_{\text {cr }}$ for the SCF3 mixture compared with all 


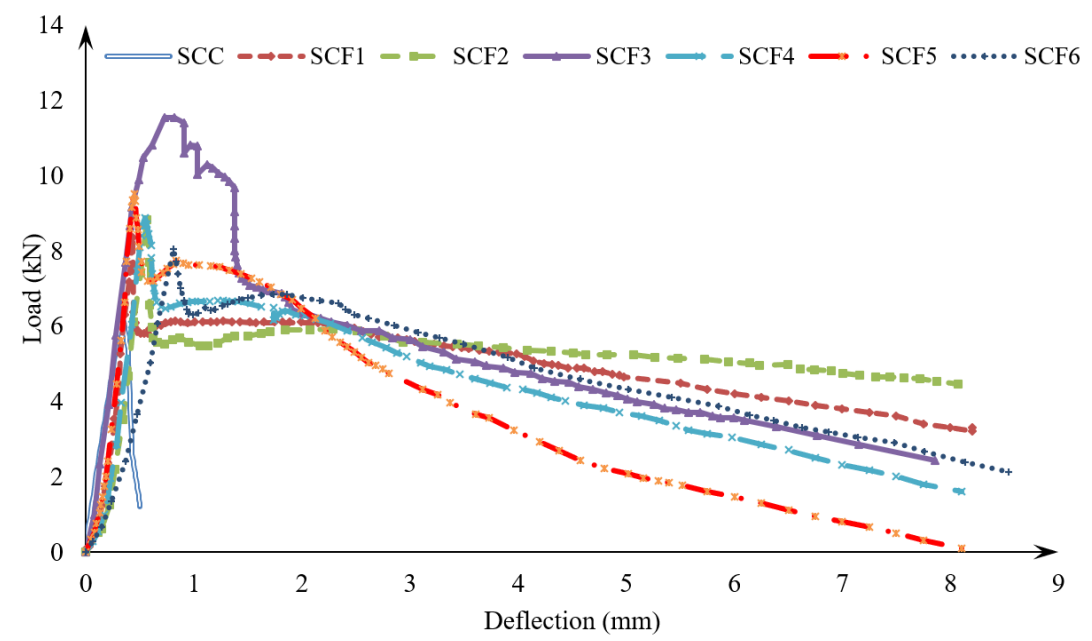

Fig. 11. Flexural load-deflection curve of all concrete mixtures. SCC, self-compacting concrete; SCF, fiberreinforced SCC.

the other mixtures. Regarding toughness indices, the highest values of $I_{5}$ were recorded in the SCF2 mixture, and the increase ratios were $15.3 \%, 70 \%$, $16.9 \%, 9.9 \%$, and $12 \%$ for SCF1, SCF3, SCF4, SCF5, and SCF6 mixtures, respectively. Also, a similar result can be observed for $I_{10}$ and $I_{20}$ in the $\mathrm{SCF} 2$ mixture, with various increase ratios ranging from $15.8 \%$ to $116.1 \%$ and from $22.2 \%$ to $179.8 \%$ for $I_{10}$ and $I_{20}$, respectively, compared with all the other mixtures Figure 13A-C. Regarding residual strength factors $\left(R_{5,10}\right.$ and $\left.R_{10,20}\right)$, the same as toughness indices, the highest $R_{5,10}$ and $R_{10,20}$ value was recorded in the SCF2 mixture, while the lower value was recorded in the SCF3 mixture, as shown in Figure 13D,E.

Regarding the length of hooked fibers effect (i.e., SF1 and SF3), the increasing length of the hooked-end fibers (i.e., SCF1) resulted in increasing toughness significantly (ranging from $47.53 \%$ to $128.96 \%$ ) compared with SCF3; the results were well consistent with the results in [44]. As evidenced from Figure 13, the smaller hooked fiber (i.e., SCF3) showed a high area under curves compared with SCF1. Despite this increase, the toughness indices and residual strength factors for SCF1 (i.e., longer hooked fiber) were higher than SCF3. On the other hand, the long straight fiber (i.e., SCF5) showed a high first-crack load compared with SCF4 (i.e., smaller straight fiber), with slight differences of over $6.9 \%$ only, while the highest first-crack displacement was recorded in SCF4 with increased ratio $24.4 \%$ compared with SCF5. Thus, it must be observed that the straight fibers' aspect ratio can affect the performance of hardened and fresh concrete considerably. It is not practical, however, to assess the values of the aspect ratio via comparing the flat and hooked end fibers' performance versus straight fibers.

\subsubsection{According to ACI 544 method}

According to ACI 544 [45], the toughness index can be defined as the ratio of the measure of the energy required to deflect a fiber concrete beam by a given amount of the energy required to bring the fiber beam to the point of the first crack. Figure 14 shows the definition of the toughness index based on ACI 544 [45], which can be measured by the area under the load-deflection curve up to a deflection of $1.9 \mathrm{~mm}\left(\delta_{1.9} \mathrm{~mm}\right)$ divided by the area under the load-deflection curve up to the first-crack deflection $\delta_{\text {cr }}$ of fiber concrete beam (as described in Eq. (8)), which is affected by the properties of concrete and the properties of fiber geometry. The calculated values of toughness indices indicated that the highest value was recorded in the SCF1 mixture, while the lower value was recorded in the SCF3 mixture, as shown in Figure 15. Also, SCF5 shows a slight difference of $6.44 \%$ only compared 


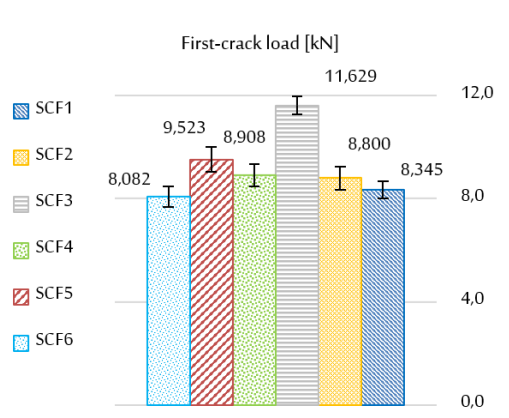

(a)

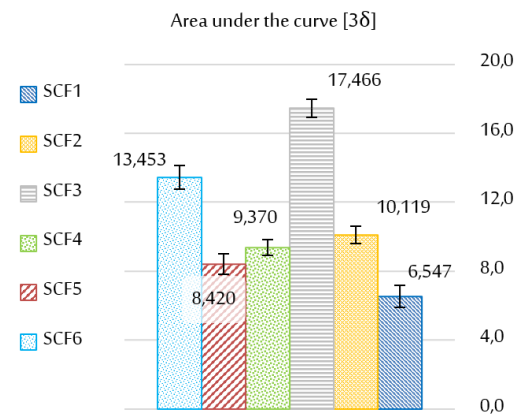

(d)

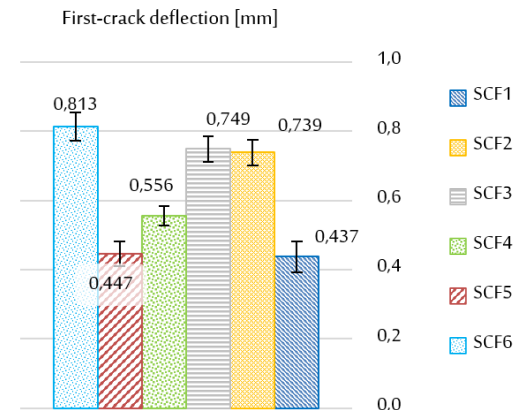

(b)

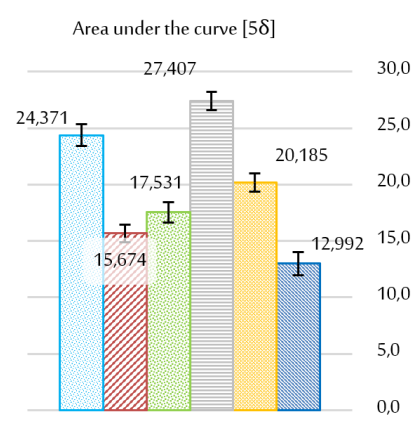

(e)

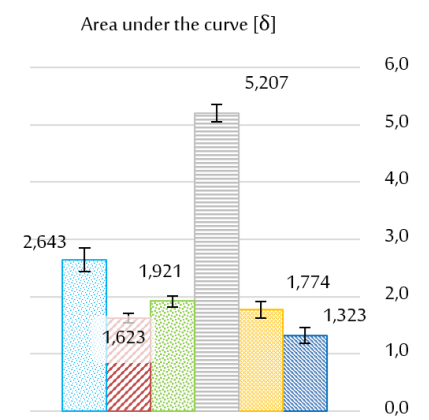

(c)

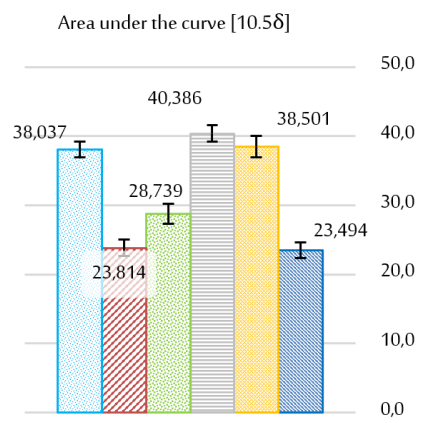

(f)

Fig. 12. First-crack loads and areas under the curve comparison of all concrete mixtures: (A) first-crack load; (B) first-crack deflection; (C) area under the curve of $\delta$; (D) area under the curve of $3.5 \delta$; (E) area under the curve of $5.5 \delta ;(\mathrm{F})$ area under the curve of $10.5 \delta$.

with SCF1. Moreover, SCF2 and SFC4 show close results with a slight difference of about $2.76 \%$ only.

$$
I=\frac{\text { Area }_{\mathrm{OABCEO}}}{\text { Area }_{\mathrm{OADO}}}
$$

\subsubsection{Load-deflection behavior}

The performance of concrete mixtures with and without fibers had significant differences which can be observed in the load-deflection curves, firstcrack load, and toughness indices. Thus, a standardized method for evaluating the beams' energy absorption capacity can be conducted by calculating specified areas under the load-induced flexural deflection curve. Load-deflection curves were obtained from the result of the flexure test of beams under three-point loading, as shown in Figure 11. As shown in Figure 11, all the concrete mixtures containing fibers (i.e., SCF1 to SCF6) showed more ductile behavior and more deformation (i.e., the failure propagation has been more uniform and gradual) compared with conventional concrete (SCC), which fails in a brittle at the formation of the first crack. Primarily, the behavior of loaddeflection is perfectly elastic up until the first-crack load. The curve growth in this segment is steeply linear. The slope of the load-deflection behavior decreased due to concrete cracking and hence exhibited a nonlinear behavior. The presence of fibers led to increase in first-crack strength through the bridging effect for all concrete mixtures compared with SCC as shown in Figures 11 and 12. After this load level, the deflection of all beams continued with a considerable decrease in the applied load. After the maximum load capacities, as shown in Figure sudden drop was observed in the resisting force for SCC due to the significantly continued extent and widening of the first-crack, which ended once the crack achieved its maximum extent at the end of the beam's cross-section. Fiber only sus- 


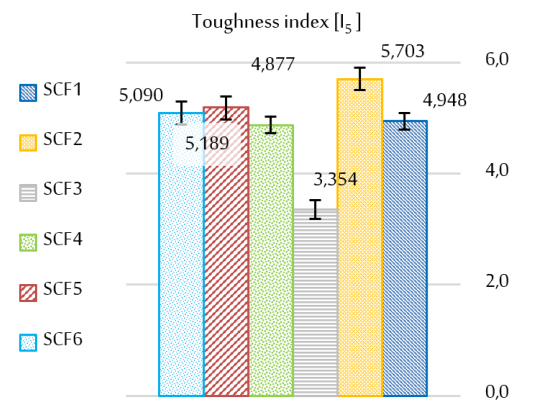

(a)

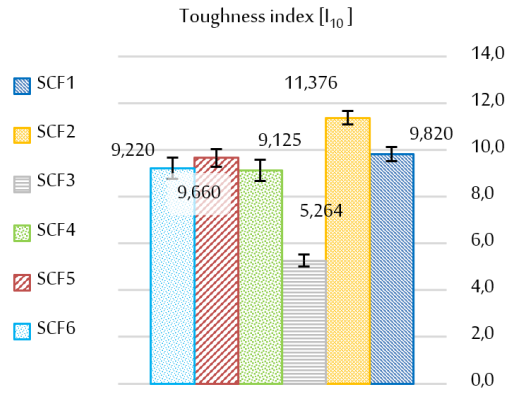

(b)

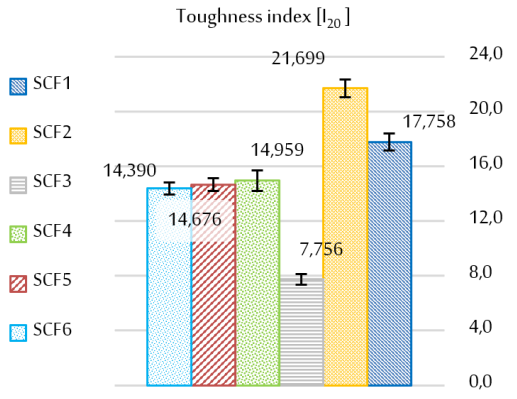

(c)

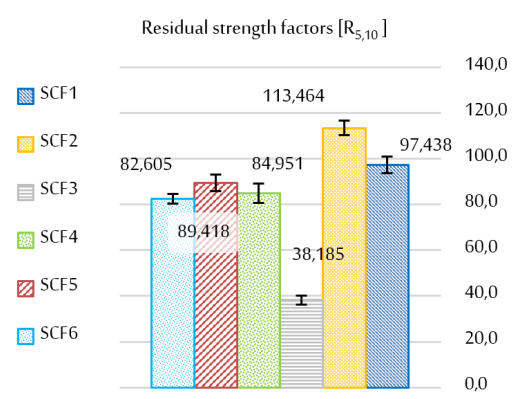

(d)

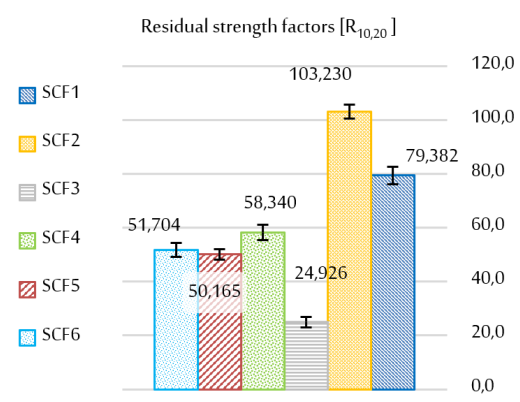

(e)

Fig. 13. Toughness indices and residual strength factors comparison of all concrete mixtures: (A) toughness index $-I_{5}$; (B) toughness index $-I_{10}$; (C) toughness index $-I_{20}$; (D) residual strength $-R_{5,10}$; (E) residual strength $-R_{10,20}$.

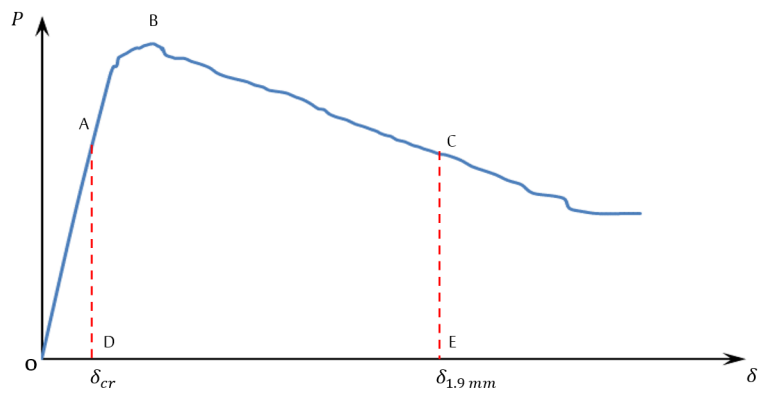

Fig. 14. Flexural toughness indices according to ACI 544 [45].

tained load after cracking via mechanical interlock and the friction at the fiber-matrix interface. Moreover, the curve's descending part showed that SF were pulled out gradually from the matrix, which is consistent with [46]. Also, the load-deflection curves' comparison showed a substantial improvement regarding all concrete mixtures' inelastic behavior, which contain fibers, whereby fibers can carry tensile forces as in the conventional rein-

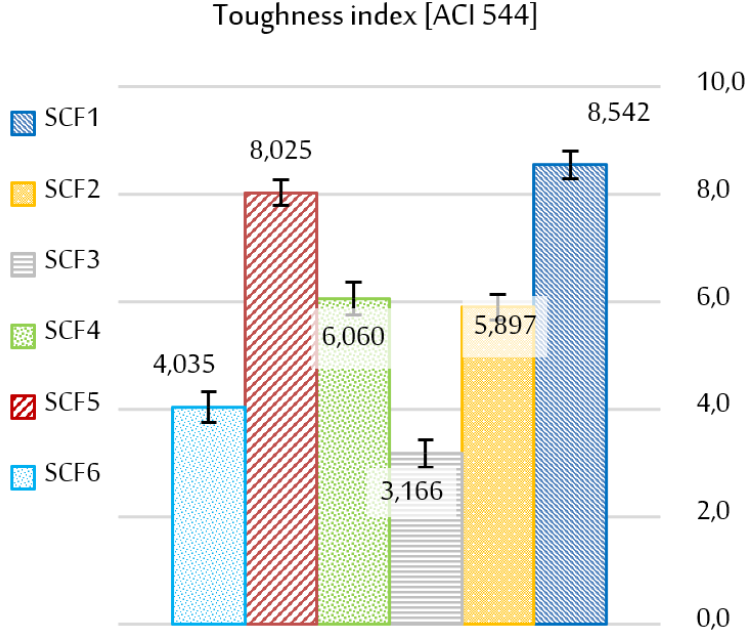

Fig. 15. Toughness indices comparison of all concrete mixtures. SCF, fiber-reinforced SCC.

forced concrete. In the latter case, therefore, there was an obvious post-cracking response through delaying the decline rate of the load-deflection curve up until the fibers' rupture or slipping. This showed 
that concrete with fibers is highly flexible, and it is more able to absorb energy than the conventional concrete mixture [47]. The load-deflection curve of SCF3 declines slowly and covers a significant area greater than the other fiber types. It also means that the hooked end fiber with a lower aspect ratio can provide higher energy absorption capacity than the other fiber types. This is attributed to the distinct bonding performance between differentshaped steel fiber and concrete matrix sustaining the load at cracks. The results were consistent with those mentioned in [48], while SCF2 shows the highest deformation capacity and the best flexural toughness of all the concrete mixtures. In the meantime, hybrid fiber concrete (SCF6) provided good flexural toughness, as well as better anti-crack performance when compared to single-fiber concrete. This is because it contains different fiber types, which showed the greatest crack bridging.

\section{Summary and conclusion}

This study has experimentally investigated the behavior of SCC containing SF, in addition to VPP as partial replacement of cement mass. The following conclusions were accordingly obtained:

- The workability of the mixture has been poorly influenced by the fibers' presence, which led to less SCC flowability. In general, no difficulty in finishing and placing was observed. The results confirm that SF can be used to reduce the segregation and bleeding rate in the SCC.

- The absorption and porosity of SCC increased with the addition of SF to the mixtures. The compressive strength of all SCF mixtures increased, ranging from $8 \%$ to $23 \%$, compared with the SCC. In contrast, the indirect tensile strength increased significantly in the SCF mixtures, by up to $28 \%$.

- The fibers' presence led to increasing the first-crack strength via the bridging effect of all the concrete mixtures versus SCC.

- According to the ASTM toughness indices, the addition of SF in SCC led to increased toughness index and residual strength factors. Also, the SCF2 exhibited the highest toughness index and residual strength factors compared with all the mixtures.

- The increasing length of the hooked-end fibers resulted in increasing toughness significantly. On the other hand, the long straight fiber showed a high first-crack load compared with the smaller straight fiber.

- The calculated values of toughness indices according to the ACI 544 indicated that the highest value was recorded in the SCF1 mixture, while the lower value was recorded in the SCF3 mixture.

- All SCF mixtures showed further ductile behavior and further deformation (i.e., the failure propagation has been further uniform and more gradual) versus the SCC conventional concrete, which experienced failure in a brittle at first-crack formation.

- A comparison of the curves of loaddeflection showed an important improvement in all concrete mixtures' inelastic behavior, which contains fibers as they can carry tensile forces like the conventional reinforced concrete. In the latter case, thus, there was an obvious post-cracking response through delaying the decline rate of the load-deflection curve up until the fibers rupture or slipping.

- As can be observed, the SCC that contains small hooked-end fibers (SFC3) recorded the highest peak load. However, the SCC that contains straight fibers (SFC4 and SFC5) recorded the lowest peak load.

- This study advances several contributions in many aspects as follows:

a) It provides empirical evidence of the use of industrial wastes such as VPP to reduce cement consumption and produce SCC.

b) It contributes to opening up new avenues for future research to improve the properties of VPP-based SCC. 
c) It also contributes to understanding the complex nature of SFs and SCC by:

- An experimental study of the effect of the most common types of SFs on fresh and hardened properties of the VPP-based SCC.

- An experimental study of the flexural toughness properties of VPP-based SCC.

\section{Declaration of conflicting interests}

None.

\section{References}

[1] ACI, ACI Committee report 237R-07 Self-consolidating concrete. ASTM International, West Conshohocken, PA. 2007.

[2] Uysal M, Yilmaz K. Effect of mineral admixtures on properties of self-compacting concrete. Cem Concr Compos. 2011;33(7):771-6.

[3] Jalal M, Pouladkhan A, Harandi OF, Jafari D. Comparative study on effects of Class F fly ash, nano silica and silica fume on properties of high performance self compacting concrete. Constr Build Mater. 2015;94:90-104.

[4] Dadsetan S, Bai J. Mechanical and microstructural properties of self-compacting concrete blended with metakaolin, ground granulated blast-furnace slag and fly ash. Constr Build Mater. 2017;146:658-667.

[5] Siddique R. Properties of concrete made with volcanic ash. Resour Conserv Recycl. 2012;66:40-4.

[6] Al-Fadala S, Chakkamalayath J, Al-Bahar S, Al-Aibani A, Ahmed S. Significance of performance based specifications in the qualification and characterization of blended cement using volcanic ash. Constr Build Mater. 2017;144:532-40.

[7] Etli S, Cemalgil S, Onat O. Effect of pumice powder and artificial lightweight fine aggregate on self-compacting mortar. Comput Concr. 2021;27(3):241-52.

[8] Granata MF. Pumice powder as filler of self-compacting concrete. Constr Build Mater. 2015;96:581-90.

[9] Pekmezci B, Akyüz S. Optimum usage of a natural pozzolan for the maximum compressive strength of concrete. Cem Concr Res. 2004;34(12):2175-9.

[10] Lemougna PN, Wang KT, Tang Q, Nzeukou AN, Billong $\mathrm{N}$, Chinje Melo U, et al. Review on the use of volcanic ashes for engineering applications. Resour Conserv Recycl. 2018;137:177-90.

[11] Celik K, Jackson MD, Mancio M, Meral C, Emwas A$\mathrm{H}$, Mehta PK, et al., High-volume natural volcanic pozzolan and limestone powder as partial replacements for Portland cement in self-compacting and sustainable concrete. Cem Concr Compos. 2014;45:136-47.

[12] Tran Q, Ghosh P. Influence of pumice on mechanical properties and durability of high performance concrete. Constr Build Mater. 2020;249:118741.
[13] Buratti N, Mazzotti C, Savoia M. Post-cracking behaviour of steel and macro-synthetic fibre-reinforced concretes. Constr Build Mater. 2011;25(5):2713-22.

[14] Dhonde HB, Mo YL, Hsu TTC, Vogel J. Fresh and hardened properties of self-consolidating fiber-reinforced concrete. ACI Mater Journal. 2007;104(5):491.

[15] Najafiyan M, Bagheri Z, Ghasemi A, Rashnavadi A. Comparison study on concretes containing fibers to provide concrete with high resistance. World Appl Sci J. 2013;24(8):1106-10.

[16] Katzer J, Domski J. Quality and mechanical properties of engineered steel fibres used as reinforcement for concrete. Constr Build Mater. 2012;34:243-48.

[17] Zemir I, Debieb F, Kenai S, Ouldkhaoua Y, Irki I. Strengthening of ordinary vibrated concrete using steel fibers self-compacting concrete. J Adhes Sci Technol. 2020;34(14):1556-1571.

[18] Madandoust R, Mohammad Ranjbar M, Ghavidel R. Assessment of factors influencing mechanical properties of steel fiber reinforced self-compacting concrete. Mater Des. 2015;83:284-94.

[19] Soroushian P, Bayasi ZJMJ. Fiber type effects on the performance of steel fiber reinforced concrete. ACI Mater J. 1991;88(2):129-34.

[20] Ponikiewski T, TJMBM. The workability of steel fibre reinforced self-compacting concrete; Modern Buildind Materials, Structures Techniques. Vilnius Gediminas Technical University. 2010. pp. 264-269.

[21] Martinie L, Roussel N. Simple tools for fiber orientation prediction in industrial practice. Cem Concr Res. 2011;41(10):993-1000.

[22] ASTM-C150. Standard test method for Portland cement. West Conshohocken, PA, US: American Society for Testing and Materials; 2007

[23] Zeyad AM, Tayeh BA, Yusuf MO. Strength and transport characteristics of volcanic pumice powder based high strength concrete. Constr Build Mater. 2019;216:314-24.

[24] BS. Chemical analysis of refractory products by X-ray fluorescence (XRF). Fused cast-bead method. In: BS EN ISO 12677:2011. London, UK: BSI; 2011. p. 86.

[25] ASTM-C33. Standard specification for concrete aggregates. West Conshohocken, PA, US: American Society for Testing and Materials; 2016.

[26] Khaloo A, Raisi EM, Hosseini P, Tahsiri H. Mechanical performance of self-compacting concrete reinforced with steel fibers. Constr Build Mater. 2014;51:179-86.

[27] ACI-211. Standard practice for selecting proportions for normal, heavyweight and mass concrete. Farmington Hills, MI, USA: American Concrete Institute; 1991.

[28] ACI-308. Guide to curing concrete. 2001 reapproved. Farmington Hills, MI, USA: American Concrete Institute; 2008.

[29] EFCAA. The European guidelines for self-compacting concrete, specification, production and use. Fernham , UK. Citeseer, 2005. https://efnarc.org/

[30] ASTM-C1610. Standard test method for static segrega- 
tion of self-consolidating concrete using column technique. West Conshohocken, PA, US: American Society for Testing and Materials; 2017.

[31] ASTM-C232. Standard specification for bleeding of concrete. West Conshohocken, PA, US: American Society for Testing and Materials; 2014.

[32] ASTM-C39. Standard test method for compressive strength of cylindrical concrete specimens. West Conshohocken, PA, US: American Society for Testing and Materials; 2015a.

[33] ASTM-C496. Standard test method for splitting tensile strength of cylindrical concrete specimens. West Conshohocken, PA, US: American Society for Testing and Materials; 2011.

[34] ASTM-C78. Standard test method for flexural strength of concrete (using simple beam with third-point loading). West Conshohocken, PA, US: American Society for Testing and Materials; 2015a.

[35] ASTM-C1018. Standard test method for flexural toughness and first-crack strength of fiber-reinforced concrete (using beam with third-point loading). West Conshohocken, PA, US: American Society for Testing and Materials; 1997.

[36] Abbass W, Khan MI, Mourad S. Evaluation of mechanical properties of steel fiber reinforced concrete with different strengths of concrete. Constr Build Mater. 2018;168:556-69.

[37] Iqbal S, Holschemacher K, Ali A, Bier TA. Mechanical properties of steel fiber reinforced high strength lightweight self-compacting concrete (SHLSCC). Constr Build Mater. 2015;98:325-33.

[38] Zeyad AM. Effect of fibers types on fresh properties and flexural toughness of self-compacting concrete. J Mater Res Technol. 2020;9(3):4147-58.

[39] Zeyad AM, Abutaleb A. Influence of steel fiber volume and volcanic pumice powder on selfconsolidating concrete properties. J King Abdulaziz Univ Eng Sci. 2020;31(1):16.

[40] Alwesabi EA, Abu Bakar BH, Alshaikh MH, Md
Akil H. Experimental investigation on mechanical properties of plain and rubberised concretes with steel-polypropylene hybrid fibre. Constr Build Mater. 2020;233:117194.

[41] Zeyad AM, Almalki A. Role of particle size of natural pozzolanic materials of volcanic pumice: flow properties, strength, and permeability. Arab J Geosci. 2021;14(2):1-11.

[42] Li B, Xu L, Shi Y, Chi Y, Liu Q, Li C. Effects of fiber type, volume fraction and aspect ratio on the flexural and acoustic emission behaviors of steel fiber reinforced concrete. Constr Build Mater. 2018;181:474-86.

[43] Alwesabi EA, Alshaikh IMH, Abu Bakar BH, Md Akil $\mathrm{H}$. Impact resistance of plain and rubberized concrete containing steel and polypropylene hybrid fiber. Mater Today Commun. 2020;25:101640.

[44] Pająk M, Ponikiewski T. Flexural behavior of selfcompacting concrete reinforced with different types of steel fibers. Constr Build Mater. 2013;47:397-408.

[45] ACI-544. Measurement of properties of fiber reinforced concrete. (Reapproved 1999). USA: American Concrete Institute; 1989.

[46] Yazıcı H, Yardımcı MY, Aydin S, Karabulut AŞ. Mechanical properties of reactive powder concrete containing mineral admixtures under different curing regimes. Constr Build Mater. 2009;23(3):1223-31.

[47] Wu Z, Shi C, He W, Wu L. Effects of steel fiber content and shape on mechanical properties of ultra high performance concrete. Constr Build Mater. 2016;103:8-14.

[48] Abu-Lebdeh T, Hamoush S, Heard W, Zornig B. Effect of matrix strength on pullout behavior of steel fiber reinforced very-high strength concrete composites. Constr Build Mater. 2011;25(1):39-46. 